\title{
An Experimental Study of Behavioral Mechanisms of Relationships between Red Wood Ants and Ground Beetles
}

\author{
E. A. Dorosheva and Zh. I. Reznikova \\ Institute of Animal Systematics and Ecology, Siberian Division, Russian Academy of Sciences, Novosibirsk 630091, Russia
}

\author{
Received November 30, 2004
}

\begin{abstract}
Behavioral mechanisms regulating the competitive relations between the red wood ant Formica aquilonia and the ground beetles Carabus regalis, Pterostichus melanarius, P. magus, P. oblongopunctatus, Harpalus smaragdinus, and Amara nitida were studied by artificially initiated collisions between living insects as well as with the use of imitation models. Members of different functional groups within an ant family (aphid-milkers, hunters, and guards) behaved differently towards beetles. Active ants were shown to respond selectively to different features of the possible competitors, such as coloration, the presence of "appendages" (legs, antennae), body symmetry, rate of movement, and scent. Field and laboratory experiments demonstrated the ability of beetles to avoid collisions with active ants. The scent of anthill material attracted ground beetles, which consumed dead ants. The gained individual experience may allow the beetles to use supplementary forage resources in the territories controlled by ants. The flexible tactical patterns facilitate spatial segregation of ground beetles and ants in the same territory and result in a more complete utilization of food resources.
\end{abstract}

DOI: $10.1134 / \mathrm{S} 0013873806020035$

Red wood ants are known to affect significantly the invertebrate fauna, not only as active predators but also as spatial competitors of predatory herpetobiotic forms, in particular spiders and beetles. The spatial distribution of these species is largely determined by the position of ant nests and the network of their foraging pathways (Cherix and Bourne, 1980; Zakharov, 1980; Suvorov, 1994; Rybalov et al., 1998; Hawes et al., 2002). Among the predatory invertebrates interacting with ants, ground beetles are characterized by broad trophic ranges, high motility, and quite flexible behavior (Sergeeva, 1992; Niemelä, 1990; Lovei and Sunderland, 1996). The effect of ants on the ground beetles is considerable: in particular, mortality among the beetles that had been even once attacked by ants was experimentally shown to be much higher than that among the intact individuals (Kolbe, 1969).

The behavioral mechanisms of competitive interactions are poorly known not only for predatory herpetobionts but also for invertebrates as a whole. T.I. Gridina $(1990,1994)$ was among the first investigators of behavioral aspects of interactions between ground beetles and ants. The beetles in her laboratory experiments showed a clear trend for evading ants. However, the behavioral responses involved were described only generally, and no species-specific behavioral traits were characterized. Our field and laboratory experiments demonstrated that ground beetles in their interactions with red wood ants used a number of tactical techniques, some of which were common to all the species studied, and some were species-specific. A single encounter with ants was shown to be sufficient for activating the behavioral patterns that allowed the beetles to avoid further conflicts (Dorosheva, 1999; Reznikova and Dorosheva, 2000, 2004).

It may be assumed that interactions between ants and ground beetles are accompanied by mutual learning that leads to "peaceful" redistribution of the insects occupying the same territory. In order to test this hypothesis, one should study interspecific communication and, in particular, find the key characters involved in the recognition of "prey" or "enemy." As concerns invertebrates, this field of behavioral ecology is still practically unknown (Reznikova, 2001).

In this work, the behavioral mechanisms involved in regulation of the competitive relations were studied by artificially initiated encounters of the ants with living competitors or imitative models. We analyzed the differences between the behavioral patterns of ants belonging to different functional groups (guards, hunters, and aphid milkers) displayed in relation to different 
trophic groups of ground beetles (predators or mixophytophages). The selectivity of ants' responses to various external characters of their potential competitors was studied, as well as the role of individual experience in development of evasion behavioral patterns in the beetles. In addition, we tested the hypothesis that ants might attract ground beetles as food objects.

\section{MATERIALS AND METHODS}

\section{Study Objects}

The study was performed in 2000-2003 in a recreational forest zone of Akademgorodok (Novosibirsk). The field experiments were carried out in the territory of a Formica aquilonia (Yarrow) colony. The test species included the ant $F$. aquilonia and six species of ground beetles differing in their size and ecological characteristics: active predators: Carabus regalis (F.-W.), Pterostichus melanarius (Ill.), P. magus (Esch.) (the most abundant species in the territory inhabited by ants), and $P$. oblongopunctatus (F.); mixophytophages with prevalence of animal or plant diet: Harpalus smaragdinus (Duft.) and Amara nitida (Sturm), respectively. The beetles were captured in pitfall traps or collected manually within the antcontrolled territory.

Several groups of ants were selected for laboratory experiments. In one set of tests, the ants were divided into groups by their aggressiveness (see Reznikova and Novgorodova, 1998), and in the other set, according to different roles in the colony. The ants to be used in the first set of tests were collected from the beginning segments of foraging pathways (1-2 $\mathrm{m}$ from the nest areas of large anthills), according to their response to a moving preparation needle. The ants were divided into four groups by their aggressiveness: (1) those seized the approaching needle in a "death grip;" (2) those bit the needle; (3) those ignored the needle and continued their movement; (4) those changed the direction to get away from the needle. For the second group of experiments (comparison of response to ground beetles in different functional groups of ants), we separately collected the "guards," active foragers ("hunters"), and "aphid milkers." The ants, which showed the greatest level of aggression toward the preparatory needle moved over the nest mound, were regarded as "guards." The "hunters" were those ants which attacked living insects specially placed at the distal segments of foraging paths. The "aphid milkers" were collected on tree trunks on their way back from aphid colonies.

To study the response of ground beetles to dead ants, the ants were placed in a Petri dish, killed with a short-term thermal impact, and allowed to cool.

\section{Study of the Selectivity of Ants with Respect to Different Species of Ground Beetles}

The aim of this study was to find out whether the ants responded selectively to different beetle species, or had a generalized aggressive response to any beetle or even to any moving object. In field experiments, beetles of different species were placed (one at a time) onto a foraging path, and the number of ants that attacked the beetle during $60 \mathrm{~s}$ was determined. These observations were carried out within the initial segments of the foraging paths, near the boundary of the nest territory, because preliminary tests showed that the ants there most readily reacted to the appearing beetles. For each of the 6 beetle species, 20 individuals were used.

In laboratory, we observed pairwise ant-beetle interactions within test areas of $15 \times 15 \mathrm{~cm}$. An ant was put in the area first, and then a beetle was placed in the opposite corner. The number of contact events, as well as the number and duration of encounters, were determined for 5 min since the latter moment. To characterize the response of ants to different species of ground beetles, we determined the number of contacts which ended in the ant attacking the beetle (A), in relation to the total number of contacts (K). If, for example, during a single test the ant and the beetle made six contacts and the ant attacked the beetle four times, then the $\mathrm{A} / \mathrm{K}$ ratio for this test was $66.7 \%$. For these tests we used the ants collected from foraging paths and assigned to group 2 by their aggressiveness. Preliminary testing of the beetles of the same six species showed that the results of laboratory and field experiments were generally similar, with the exception of C. regalis. Beetles of the latter species were subject to most frequent attacks on the foraging pathways and least frequent attacks in the test areas. This can be explained by the fact that these beetles move rather fast along the pathways but remain immobile for long periods of time in the test areas, even during contacts with the ants. Twenty individuals were tested for each of the five remaining species of ground beetles. The significance of differences in the number of ants which attacked the ground beetles on the pathways was determined using the Student's test for each pair 

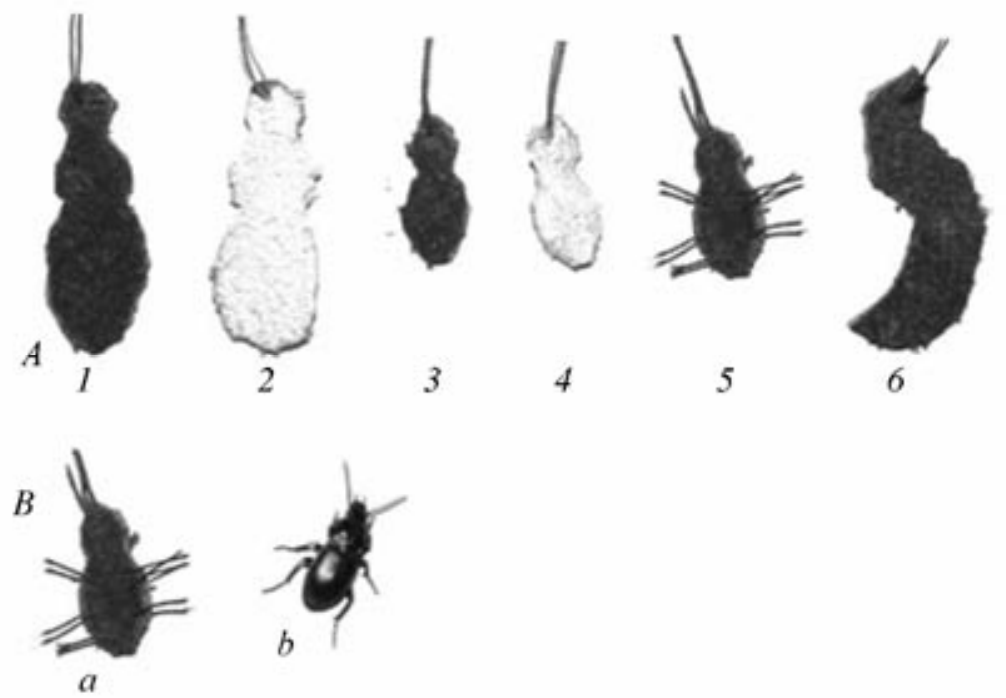

(A) Imitation models offered to ants on foraging path. Symmetrical models: dark brown, $3 \mathrm{~cm}$ long (1); white, $3 \mathrm{~cm}$ long (2); dark brown, $1.5 \mathrm{~cm}$ long (3); white, $1.5 \mathrm{~cm}$ long (4); dark brown, $1.5 \mathrm{~cm}$ long, with "legs" and "antennae" made of black thread (5). Asymmetrical model: dark brown, $3 \mathrm{~cm}$ long (6). (B) Imitation model of a beetle (a) and Pterostichus magus (b).

of species. The degree of aggressiveness of ants with respect to different beetle species in laboratory experiments was estimated by comparison of the $\mathrm{A} / \mathrm{K}$ ratios for each species pair, using the $\chi^{2}$ criterion.

\section{Description of Behavioral Responses of Insects during Encounters}

Pairwise interactions of $P$. magus beetles with ants were studied in test areas. In order to find the complete range of behavioral responses, we tested the ants differing in their aggressiveness (10 individuals from each of the 4 groups, selected as described above). All behavioral responses of the ants and beetles were recorded. The beetles which killed the ants during their first contact were subjected to the second test one hour later. In all, we carried out 40 tests, each lasting $5 \mathrm{~min}$.

To compare the responses to ground beetles in representatives of different functional groups of ants, we observed interactions between $P$. magus beetles and guards, active hunters, and aphid milkers in test areas. For each functional group, 20 ants were tested (60 tests, 5 min each).

\section{Finding the Key Characters Used in Recognition of the Beetles by the Ants}

The design of experiments using models imitating or emphasizing different characters, the response to which is studied, was first proposed by N. Tinbergen (1951) and is still widely used in ethology and behavioral ecology. The ants on their foraging pathways were offered flat models made of chamois and imitating some characters of the beetles. Five symmetrical and one asymmetrical model were used. The symmetrical models (I) had the general outlines of a beetle body and were made in several variants: (1) dark brown, $3 \mathrm{~cm}$ long; (2) white, $3 \mathrm{~cm}$ long; (3) dark brown, $1.5 \mathrm{~cm}$ long; (4) white, $1.5 \mathrm{~cm}$ long; (5) dark brown, $1.5 \mathrm{~cm}$ long, with "legs" and "antennae" made of black thread. The asymmetrical model (II) was dark brown, $3 \mathrm{~cm}$ long (6) (figure). Each of the models was tested 20 times while placed on a foraging path and left immobile, and 20 times while being moved on a thread (for a total of 240 tests). In addition, the text objects included dead $P$. magus beetles with legs and antennae (7) or with appendages removed (8); a living $C$. regalis beetle colored in white $(9)$; $C$. regalis beetles wrapped in dark cloth (10) or in white cloth (11), and also similarly sized balls of the same cloth (12, 13). In each of the 13 tests, the number of ants "interested" in the model (exploring, biting, or trying to move it) was determined during one minute.

The significance of differences in the attractiveness for the chamois models, which differed in a set of characters, was determined using Scheffe's multiple comparison test (Pollard, 1982); other models were compared pairwise using Student's test. The choice of statistical criteria was determined by different approaches to experiment planning. In the first series (chamois models), potentially important characters, such as coloration, size, and the presence of appendages, were added one at a time during consecutive 
tests. In the second series, models differing in a single character were compared (for example, cloth balls with or without scent), while the pair being tested differed from other models in many characters.

\section{Testing the Hypothesis that Ants Attract Ground Beetles as Food Objects}

The response of ground beetles to the scent of living and dead ants was studied. In the territory inhabited by $F$. aquilonia, we placed pitfall traps which contained: (1) dead $F$. aquilonia (30 insects per trap), (2) material of the ant nest mound (without ants), and (3) an equal volume of forest litter. A total of 30 pitfall traps, arranged in six rows $10 \mathrm{~m}$ apart, were installed for three 2-day periods in mid-June. The number of ground beetles captured in the traps with forest litter characterized the general dynamic density of these insects in the area. This number was compared to the number of beetles captured in the traps with dead ants and nest material. The latter number would be smaller if the scent of ants repelled the beetles, and greater if it attracted them. In order to find out whether the response of the beetles was generalized or related to a particular ant species, pitfall traps with dead $F$. pratensis ants were exposed in the same area; these ants inhabited a steppe biocenosis and could not have been previously met by the beetles in the study area (Variant 1). Pitfall traps containing dead $F$. aquilonia were used for comparison (Variant 2), and empty ones, as controls (Variant 3). Thirty pitfall traps, arranged in the same way as in the first series of experiments, were installed for three 2-day periods. The number of ground beetles captured was recorded. In both series, the significance of differences between the numbers of beetles captured (Variants 1-3) was determined using Student's test.

In laboratory experiments, we studied the ability of ground beetles to hunt living ants and to feed on dead ones. P. magus beetles, which had previously encountered ants in the test areas, were starved (given only water) for three days and then offered dead or living ants ( 20 beetles in each variant). Each beetle and 3 ants (living or dead) were kept for 24 hours in a glass vial containing humid forest litter, with a perforated cover to provide ventilation. The ants were preliminarily tested using the preparatory needle to select the least aggressive ones (grades 3-4), so as to prevent the death of the ants as a result of their attacks on the beetle. The same design was used in experiments with C. regalis beetles, which were captured in pitfall traps and starved for three days. Five of these beetles were offered living ants, and five, dead ones.

\section{RESULTS}

\section{Behavior of Insects during Encounters}

Observations of the behavior of $P$. magus and the ants during encounters allowed us to find stable behavioral patterns displayed by ants encountering beetles (here referred to as tactical patterns), as well as stable tactical patterns of beetles encountering ants.

The following tactical patterns can be observed in ants upon their contact with a ground beetle: (I) "death grip" (the ant grasps the beetle and does not let go); (II) "long" attacks (attacks lasting more than $5 \mathrm{~s}$, after which the ant releases the beetle and gets away); (III) "short" attacks (attacks lasting less than $5 \mathrm{~s}$ ); (IV) indifference (the ant shows no response at all, or explores the beetle with its antennae and moves on); (V) evasion (the ant changes direction and increases the rate of its movement during or immediately before contact with the beetle, to evade the encounter).

The beetles showed the following patents of interaction with ants:

(A) Prior to encounter with an ant: (1) no changes in the direction and movement rate (the beetle does not evade direct contact); (2) change in the direction and increase in the movement rate to evade contact; (3) stop (which often allows the beetle to avoid contact).

(B) During encounter with an ant: (1) the beetle increases its movement past the ant; (2) the beetle stops and assumes the least vulnerable posture (with its legs and antennae closely pressed to the body); (3) the beetle participates in an "aggressive" contact.

We recorded changes in the behavior of the beetle during the test (after one or several contacts with an ant) and compared them with the tactical pattern shown by the ant. Each ant and each beetle usually displayed several tactical patterns in the course or their interaction. In order to find out how the behavior of the ant affects the development of a conflict evasion pattern in the beetle, we determined the prevalent tactical pattern of the ant. The prevalent pattern was the one displayed in more than $50 \%$ of the encounters. For example, if the ant and beetle met 11 times during the 5 -min test period, and the ant displayed pattern 2 seven times, pattern 1 three times, and pattern 3 once, then pattern 2 was considered the prevalent one. If the 
frequencies of two patterns were close to $50 \%$, both patterns were regarded as prevalent. Such a situation was observed only for patterns 4 and 5 .

After several contacts (1-4) with ants during the test, many beetles started to display behavioral patterns aimed at evading such contacts (changing the direction and increasing the rate of movement, or stopping before encounter). In the cases when such patterns were present in the beginning of the test period, their frequency increased. This allowed the beetles to avoid conflicts. Behavioral changes were most profound in those beetles which met the ants with a "death grip" as the principal tactical pattern. The attacks of ants lasted from 40 to $240 \mathrm{~s}$, and 7 ants out of 8 died after the first attack. Such encounters appear to have the greatest "teaching" effect for the ground beetles. All the 8 individuals of $P$. magus started to evade contacts with ants already after the first attack, which became evident in the first encounter with another ant. In the cases when the ants attacked the beetles and then got out, more than half of the beetles (among the 18 individuals tested) also started to evade contacts (Table 1). It is interesting that none of the 12 beetles that interacted with indifferent or contact-avoiding ants showed any changes in their behavior during the entire test period.

\section{Selectivity of the Ants in Relation to the Ground Beetles and the Objects with Principal Characters of Beetles}

In laboratory experiments, the ratio between the number of attacks of the ant on the beetle and the total number of contacts was the highest for three predatory species of Pterostichus, which are about the same size as the ants. No significant difference was observed between the degrees of aggressiveness in relation to these three beetle species (Tables 2, 3). The aggressiveness of ants in relation to the mixophytophagous $A$. nitida and $H$. smaragdinus was significantly lower.

In field experiments carried out in the foraging pathways of ants, $C$. regalis was attacked most frequently, the second place was occupied by $P$. magus, and the least frequently attacked species was $A$. nitida (Tables 2, 4). Significant differences were found between the responses of ants to $C$. regalis, $P$. magus, $A$. nitida, on the one hand, and $P$. melanarius, $P$. oblongopunctatus, and $H$. smaragdinus, on the other hand (beetles of the three last species were attacked by the same number of ants, which, however, differed from the number of ants attacking other species). Direct
Table 1. Activation of evasion pattern in ground beetles in relation to prevalent behavior of ant

\begin{tabular}{l|c|c|c|c|c|c}
\hline \multirow{2}{*}{ Parameter } & \multicolumn{6}{|c}{ Behavioral pattern of the ant } \\
\cline { 2 - 7 } & I & II & III & IV & V & IV, V* \\
\hline $\begin{array}{l}\text { Number of ants with pre- } \\
\text { valence of a specific } \\
\text { pattern }\end{array}$ & 8 & 4 & 16 & 3 & 4 & 5 \\
$\begin{array}{l}\text { Number of ground bee- } \\
\text { tles which started to } \\
\text { evade encounters with } \\
\text { ants (after 1-4 attacks) }\end{array}$ & 8 & 2 & 9 & 0 & 0 & 0 \\
\hline
\end{tabular}

Notes. "Death grip" (I), "long" attacks (II), "short" attacks (III), indifference (IV), evasion (V); * individuals that displayed both patterns (IV and V).

Table 2. Aggressiveness of ants in relation to different species of ground beetles

\begin{tabular}{l|c|c}
\hline \multirow{2}{*}{\multicolumn{1}{c|}{ Species }} & \multicolumn{2}{|c}{ Attacks by ants $(n=20)$} \\
\cline { 2 - 3 } & in test areas* & $\begin{array}{c}\text { on foraging } \\
\text { paths** }\end{array}$ \\
\hline Pterostichus magus & $0.56 \pm 0.14$ & $11.3 \pm 2.3$ \\
P. melanarius & $0.62 \pm 0.12$ & $7.7 \pm 2.4$ \\
P. oblongopunctatus & $0.51 \pm 0.12$ & $7.9 \pm 1.4$ \\
Carabus regalis & $0.18 \pm 0.13$ & $26.9 \pm 3.3$ \\
Amara nitida & $0.29 \pm 0.08$ & $4.0 \pm 1.1$ \\
Harpalus smaragdinus & $0.32 \pm 0.10$ & $7.3 \pm 1.3$ \\
\hline
\end{tabular}

Notes. *Fraction of attacks in the total number of contacts between ants and beetles in test areas; ** the number of ants attacked beetles on foraging path.

antennal contacts were observed during the encounters with $H$. smaragdinus (7 cases in 132 encounters) and A. nitida (5 cases in 117 encounters).

Laboratory experiments demonstrated significant differences in responses to beetles showed by the ants belonging to different functional groups. The hunters and guards attacked the beetles with nearly the same frequency (in $50 \pm 12 \%$ and $55 \pm 16 \%$ of cases, respectively), and the aphid milkers attacked very rarely $(0.23 \pm 0.10 \%)$. The distribution of tactical patterns in relation to the beetles was found to be similar in the hunters and guards, whereas the aphid milkers showed a different behavior. In particular, the aphid milkers never used the "death grip" pattern, and the evasion pattern prevailed in more than half of these individuals (Table 5).

With the use of the imitation models differing in particular characters, the following trends were found (see Tables 6, 7). Coloration and movement obviously 
Table 3. Significance of differences in aggressiveness of ants in relation to different species of ground beetles in test $\operatorname{areas}\left(\chi^{2}\right)$

\begin{tabular}{c|c|c|c|c|c|c}
\hline $\begin{array}{r}\text { Spe- } \\
\text { cies }\end{array}$ & 1 & 2 & 3 & 4 & 5 & 6 \\
\hline 1 & $\#$ & 0.93 & 0.9 & $\mathbf{1 8 . 8}^{* *}$ & $\mathbf{2 8 . 3}^{* *}$ & $\mathbf{2 8 . 8}^{* *}$ \\
2 & 0.93 & $\#$ & 1.6 & $\mathbf{1 9 . 6}^{* *}$ & $\mathbf{2 5 . 6}^{* *}$ & $\mathbf{2 5 . 7} * *$ \\
3 & 0.90 & 1.6 & $\#$ & $\mathbf{1 2 . 1}^{* *}$ & $\mathbf{1 2 . 4}^{* *}$ & $\mathbf{1 2 . 4}^{* *}$ \\
4 & $\mathbf{1 8 . 8}^{* *}$ & $\mathbf{1 9 . 6}^{* *}$ & $\mathbf{1 2 . 1}^{* *}$ & $\#$ & $\mathbf{6 . 5}^{*}$ & $\mathbf{6 . 6}^{* *}$ \\
5 & $\mathbf{2 8 . 3}^{* *}$ & $\mathbf{2 5 . 6}^{* *}$ & $\mathbf{1 2 . 4}^{* *}$ & $\mathbf{6 . 5}^{*}$ & $\#$ & 1.9 \\
6 & $\mathbf{2 8 . 8}^{* *}$ & $\mathbf{2 5 . 7}^{* *}$ & $\mathbf{1 2 . 4}^{* *}$ & $\mathbf{6 . 6}^{* *}$ & 1.9 & $\#$ \\
\hline
\end{tabular}

Notes. Pterostichus magus (1), P. melanarius (2), P. oblongopunctatus (3), Carabus regalis (4), Amara nitida (5), and Harpalus smaragdinus (6). The species are enumerated in rows and columns; the index of aggressiveness was calculated as fraction of attacks by ants in the total number of contacts; the significant values are shown in bold. $* p<0.05 ; * * p<0.01$.

Table 4. Significance of differences in aggressiveness of ants in relation to different species of ground beetles on foraging paths (Student's $t$ test)

\begin{tabular}{c|c|c|c|c|c|c}
\hline $\begin{array}{c}\text { Spe- } \\
\text { cies }\end{array}$ & 1 & 2 & 3 & 4 & 5 & 6 \\
\hline 1 & $\#$ & $\mathbf{- 2 . 3} * *$ & $\mathbf{- 2 . 7}$ & $\mathbf{8 . 1} * *$ & $\mathbf{- 6 . 0} * *$ & $\mathbf{- 3 . 2} * *$ \\
2 & $\mathbf{2 . 3} * *$ & $\#$ & -0.2 & $\mathbf{9 . 9} * *$ & $\mathbf{- 2 . 9}^{* *}$ & -0.3 \\
3 & $\mathbf{2 . 7}$ & 0.19 & $\#$ & $\mathbf{1 0 . 9}^{* *}$ & $\mathbf{- 4 . 5}^{* *}$ & -0.7 \\
4 & $\mathbf{- 8 . 1}$ & $\mathbf{- 9 . 9 * *}$ & - & $\#$ & - & $\mathbf{- 1 1 . 6}^{* *}$ \\
& & & $\mathbf{1 0 . 9}^{* *}$ & & $\mathbf{1 3 . 6}^{* *}$ & \\
5 & $\mathbf{6 . 0}^{* *}$ & $\mathbf{2 . 9 * *}$ & $\mathbf{4 . 5}^{* *}$ & $\mathbf{1 3 . 6}^{* *}$ & $\#$ & $\mathbf{4 . 1}^{* *}$ \\
6 & $\mathbf{3 . 2}^{* *}$ & 0.3 & 0.7 & $\mathbf{1 1 . 6}^{* *}$ & $\mathbf{- 4 . 1}^{* *}$ & $\#$ \\
\hline
\end{tabular}

Notes. The species are enumerated in rows and columns, as in Table 3; the significant values are shown in bold. ${ }^{*} p<0.05$; ** $p<0.01$.

increased the attractiveness of the models, while their size differently affected the response of the ants. Among the dark and immobile models, larger ones attracted the ants more strongly than did smaller ones. However, among mobile models, smaller ones were more attractive. Light colored models attracted almost no attention, regardless of their size and mobility. The presence of "legs" and "antennae" was a significant character, which increased the activity of both immobile and mobile models. The ants tried to bite the "appendages" or the thread with which the model was moved. Other models (without "appendages") were only examined by the ants during 1-3 $\mathrm{s}$. The presence or absence of bilateral symmetry was also significant: the asymmetrical models proved to be less attractive than symmetrical ones of the same size.
Dead beetles (immobile objects), with or without legs and antennae, were rather attractive to the ants $(24.4 \pm 1.8$ and $25.2 \pm 2.2$ attacks per minute). All the ants that approached the dead beetles, bit them and tried to move them. Experiments with $C$. regalis stained with chalk whiting showed that a light colored beetle is attacked less frequently than one of normal coloration $(8.4 \pm 1.1$ and $26.9 \pm 3.3$ attacks per minute, respectively; $p<0.01)$. The ants showed greater interest to $C$. regalis wrapped in dark cloth (i.e., to a dark ball with the scent of the beetle), than to a similarly sized ball made of the same cloth but without a beetle inside $(15.8 \pm 1.4$ and $6.7 \pm 1.1$ attacks, respectively; $p<0.01)$. The ants not only explored the ball with the beetle inside but also bit it and tried to move it. At the same time, there was no difference between $C$. regalis wrapped in white cloth and a ball of white cloth.

\section{Attractiveness of Ants as Food Objects for the Ground Beetles}

The average number of ground beetles captured in pitfall traps containing dead $F$. aquilonia was $2.5 \pm 1.0$ per 1 trap-day; in the traps containing ant nest material, $2.7 \pm 0.9$; and in the control, $1.2 \pm 0.4$. The number of beetles in the traps with dead ants and with nest material did not differ significantly, but exceeded the control values $(p<0.05)$. In the second series of experiments, the traps containing dead $F$. aquilonia yielded on the average $1.6 \pm 0.2$ beetles, those containing $F$. pratensis, $1.4 \pm 0.6$ beetles, and the control ones, $0.5 \pm 0.2$ beetles. The number of beetles captured in the traps with dead ants of both species exceeded that in the control $(p<0.05)$, while no difference was observed between the traps containing $F$. aquilonia and $F$. pratensis. Most of the captures in both series represented the common predatory species P. magus. Thus, both dead ants and the nest material were equally attractive to the ground beetles. The ants $F$. pratensis, which are absent in forest biocenoses, attracted the ground beetles living in the territory of a $F$. aquilonia colony to the same extent as $F$. aquilonia.

We tried to find out whether the ground beetles could feed on living or dead ants. In the laboratory experiments when living or dead ants were offered to the beetles, living ants were never consumed. Among the 20 individuals of $P$. magus and 5 individuals of $C$. regalis offered dead ants, they were partly or completely eaten by $15 P$. magus and all $C$. regalis. In the field and laboratory experiments, $C$. regalis, $P$. mela- 
Table 5. Distribution of behavioral patterns in ants of different functional groups

Number of ants (out of 20) with prevalence of a specific tactical pattern

\begin{tabular}{|l|c|c|c|c|c|c}
\multicolumn{1}{|c|}{ Functional group } & I & II & III & IV & V & IV, V* \\
\hline Hunters & 5 & 3 & 9 & 2 & 0 & 1 \\
Guards & 4 & 2 & 11 & 1 & 1 & 1 \\
Aphid milkers & 0 & 1 & 6 & 2 & 7 & 4 \\
\hline
\end{tabular}

Note. For I-V, see Table 1.

Table 6. Number of ants showing response to different imitation models (average value for 20 tests, 1 min each)

\begin{tabular}{l|c|c|c|c|c|c}
\hline \multirow{2}{*}{\multicolumn{1}{c|}{ Model }} & \multicolumn{7}{c}{ Model parameters } \\
\cline { 2 - 7 } & $1(\mathrm{I})$ & $2(\mathrm{I})$ & $3(\mathrm{I})$ & $4(\mathrm{I})$ & $5(\mathrm{I})$ & $6(\mathrm{II})$ \\
\hline Moved & $27.5 \pm 2.5$ & $7.3 \pm 1.5$ & $30.1 \pm 2.0$ & $6.9 \pm 1.2$ & $34.3 \pm 2.1$ & $5.0 \pm 1.5$ \\
Stationary & $23.7 \pm 1.9$ & $3.1 \pm 1.2$ & $12.9 \pm 1.4$ & $2.8 \pm 1.1$ & $15.6 \pm 2.4$ & $3.8 \pm 1.2$ \\
\hline
\end{tabular}

Notes. (I) symmetrical imitation models: dark brown, $3 \mathrm{~cm}$ long (1); white, $3 \mathrm{~cm}$ long (2); dark brown, $1.5 \mathrm{~cm}$ long (3); white, $1.5 \mathrm{~cm}$ long (4); dark brown, $1.5 \mathrm{~cm}$ long, with "legs" and "antennae" made of black thread (5). (II) asymmetrical model: dark brown, $3 \mathrm{~cm}$ long (6).

Table 7. Significance of differences in attractiveness of different imitation models to ants (Scheffe's multiple comparison test)

\begin{tabular}{c|c|c|c|c|c|c|c|c|c|c|c|c}
\hline No. & $1 \mathrm{a}$ & $1 \mathrm{~b}$ & $2 \mathrm{a}$ & $2 \mathrm{~b}$ & $3 \mathrm{a}$ & $3 \mathrm{~b}$ & $4 \mathrm{a}$ & $4 \mathrm{~b}$ & $5 \mathrm{a}$ & $5 \mathrm{~b}$ & $6 \mathrm{a}$ & $6 \mathrm{~b}$ \\
\hline $1 \mathrm{a}$ & $\#$ & 0.97 & $<\mathbf{0 . 0 1}$ & $<\mathbf{0 . 0 1}$ & 0.47 & $<\mathbf{0 . 0 1}$ & $<\mathbf{0 . 0 1}$ & $<\mathbf{0 . 0 1}$ & $<\mathbf{0 . 0 1}$ & $<\mathbf{0 . 0 1}$ & $<\mathbf{0 . 0 1}$ & $<\mathbf{0 . 0 1}$ \\
$1 \mathrm{~b}$ & 0.97 & $\#$ & $<\mathbf{0 . 0 1}$ & $<\mathbf{0 . 0 1}$ & $<\mathbf{0 . 0 1}$ & $<\mathbf{0 . 0 1}$ & $<\mathbf{0 . 0 1}$ & $<\mathbf{0 . 0 1}$ & $<\mathbf{0 . 0 1}$ & $<\mathbf{0 . 0 1}$ & $<\mathbf{0 . 0 1}$ & $<\mathbf{0 . 0 1}$ \\
$2 \mathrm{a}$ & $<\mathbf{0 . 0 1}$ & $<\mathbf{0 . 0 1}$ & $\#$ & 0.36 & $<\mathbf{0 . 0 1}$ & $\mathbf{0 . 0 4}$ & 1.00 & 0.27 & $<\mathbf{0 . 0 1}$ & $<\mathbf{0 . 0 1}$ & 0.98 & 0.67 \\
$2 \mathrm{~b}$ & $<\mathbf{0 . 0 1}$ & $<\mathbf{0 . 0 1}$ & 0.36 & $\#$ & $<\mathbf{0 . 0 1}$ & $<\mathbf{0 . 0 1}$ & 0.54 & 1.00 & $<\mathbf{0 . 0 1}$ & $<\mathbf{0 . 0 1}$ & 0.99 & 1.00 \\
$3 \mathrm{a}$ & 0.47 & $<\mathbf{0 . 0 1}$ & $<\mathbf{0 . 0 1}$ & $<\mathbf{0 . 0 1}$ & $\#$ & $<\mathbf{0 . 0 1}$ & $<\mathbf{0 . 0 1}$ & $<\mathbf{0 . 0 1}$ & 0.38 & $<\mathbf{0 . 0 1}$ & $<\mathbf{0 . 0 1}$ & $<\mathbf{0 . 0 1}$ \\
$3 \mathrm{~b}$ & $<\mathbf{0 . 0 1}$ & $<\mathbf{0 . 0 1}$ & 0.04 & $<\mathbf{0 . 0 1}$ & $<\mathbf{0 . 0 1}$ & $\#$ & $\mathbf{0 . 0 2}$ & $<\mathbf{0 . 0 1}$ & $<\mathbf{0 . 0 1}$ & 0.93 & $<\mathbf{0 . 0 1}$ & $<\mathbf{0 . 0 1}$ \\
$4 \mathrm{a}$ & $<\mathbf{0 . 0 1}$ & $<\mathbf{0 . 0 1}$ & 1.00 & 0.54 & $<\mathbf{0 . 0 1}$ & $\mathbf{0 . 0 2}$ & $\#$ & 0.43 & $<\mathbf{0 . 0 1}$ & $<\mathbf{0 . 0 1}$ & 0.99 & 0.82 \\
$4 \mathrm{~b}$ & $<\mathbf{0 . 0 1}$ & $<\mathbf{0 . 0 1}$ & 0.27 & 1.00 & $<\mathbf{0 . 0 1}$ & $<\mathbf{0 . 0 1}$ & 0.43 & $\#$ & $<\mathbf{0 . 0 1}$ & $<\mathbf{0 . 0 1}$ & 0.98 & 1.00 \\
$5 \mathrm{a}$ & $<\mathbf{0 . 0 1}$ & $<\mathbf{0 . 0 1}$ & $<\mathbf{0 . 0 1}$ & $<\mathbf{0 . 0 1}$ & 0.38 & $<\mathbf{0 . 0 1}$ & $<\mathbf{0 . 0 1}$ & $<\mathbf{0 . 0 1}$ & $\#$ & $<\mathbf{0 . 0 1}$ & $<\mathbf{0 . 0 1}$ & $<\mathbf{0 . 0 1}$ \\
$5 \mathrm{~b}$ & $<\mathbf{0 . 0 1}$ & $<\mathbf{0 . 0 1}$ & $<\mathbf{0 . 0 1}$ & $<\mathbf{0 . 0 1}$ & $<\mathbf{0 . 0 1}$ & 0.94 & $<\mathbf{0 . 0 1}$ & $<\mathbf{0 . 0 1}$ & $<\mathbf{0 . 0 1}$ & $\#$ & $<\mathbf{0 . 0 1}$ & $<\mathbf{0 . 0 1}$ \\
6a & $<\mathbf{0 . 0 1}$ & $<\mathbf{0 . 0 1}$ & 0.98 & 0.99 & $<\mathbf{0 . 0 1}$ & $<\mathbf{0 . 0 1}$ & 0.99 & 0.98 & $<\mathbf{0 . 0 1}$ & $<\mathbf{0 . 0 1}$ & $\#$ & 1.00 \\
6b & $<\mathbf{0 . 0 1}$ & $<\mathbf{0 . 0 1}$ & 0.67 & 1.00 & $<\mathbf{0 . 0 1}$ & $<\mathbf{0 . 0 1}$ & 0.82 & 1.00 & $<\mathbf{0 . 0 1}$ & $<\mathbf{0 . 0 1}$ & 1.00 & $\#$ \\
\hline
\end{tabular}

Notes. The models are enumerated as in Table 6; models moved on a thread are marked with $a$, stationary ones are marked with $b$; significant values are shown in bold.

narius, P. magus, $P$. oblongopunctatus, and $H$. smaragdinus did not attack living and active ants; however, the ants killed in the conflicts initiated by their high aggressiveness in the test areas, were consumed by the beetles.

\section{DISCUSSION}

Comparison of the frequencies of aggressive responses of ants in their encounters with six species of ground beetles shows that ants react selectively to different beetle species and more frequently attack predatory species as compared to mixophytophages. Both in laboratory test areas and in foraging paths, the ants rather frequently attack $P$. magus, which was previously shown to be the most abundant ground beetle species in the ant colony territory (Reznikova and Dorosheva, 2004). In their foraging paths, the ants more frequently attack $P$. magus than other species of Pterostichus. This trend may indicate that aggressiveness of individual ants probably depends on the frequency of encounters with the potential competitors. It is known that red wood ants can "switch" to the currently common prey species. Some dominant ant species in multi-specific communities were shown to be able to estimate and regulate the abundance of subordinate ant species; this phenomenon was referred to as 
"interspecific social control" (Reznikova, 2003). It is possible that as the dynamic density of the ground beetles in the territory occupied by ants increases, the ants become more aggressive in relation to the beetles.

At the same time, in laboratory experiments the ants attacked beetles of the three Pterostichus species with equal frequency. This can be explained by the fact that in the test areas the ants met the same beetle repeatedly within a short period, which might be perceived as indication of a "high density" of the beetles.

The lowest degree of aggression was displayed in relation to small mixophytophagous beetle $A$. nitida. Since smaller mixophytophages with less robust cuticle represent a relatively more available prey than other ground beetles, it may be assumed that aggressiveness of ants is primarily aimed at repelling the potential competitors rather than at using them as prey. At the same time, mixophytophagous ground beetles are no "easy victims" and under natural conditions do not constitute a noticeable part in the ant diet (Inozemtsev, 1974; Malozemova, 1980; Reznikova, 1983). Attempts at killing potential competitors may be dangerous for the ants as well. The observed antennal contacts between the beetles and ants suggest the existence of some stable interaction patterns.

By the example of P. magus, the behavioral patterns of ground beetles have been shown to depend on their previous experience of contacts with ants. After 1-4 contacts, the behavior of the beetle is determined by that of the ant. The "death grip" tactical pattern is the most effective one for "switching on" the pattern of ant evasion in the beetle during the subsequent encounters; at the same time, this pattern is the most dangerous for the ants themselves. This behavior is likely to be used by the ants defending their nest territory. The patterns including "short" and "long" attacks are less dangerous for the ants but their "teaching" effect is only half as great. They may be used by hunter ants within their individual areas. In the simplified environment of laboratory experiments, the hunters and guards reveal no significant behavioral differences, but under natural conditions these differences may become evident depending on the situation, for example the specific dynamic density of ants in the area where the contact occurs. Our experiments demonstrated a certain degree of flexibility in the individual behavior or ants, which, however, is not so clearly related to the behavior of the beetles as the opposite dependence, namely the changes in the beetles' response in relation to the behavior of ants. The re- sponses of the ants may be formed and stabilized at earlier stages of the imaginal development, in relation to the fixed functional segregation of individuals.

The experiments with imitation models have shown that the recognition of potential victims and competitors by ants may involve such visual characters as movement, dark color, bilateral symmetry, and the presence of appendages. It is interesting that the same principal characteristics of the "prey image" were found in vertebrates hunting insects. For example, tamarin monkeys respond to imitation insects using such characters as the presence of appendages, head, and bilateral symmetry (Robinson, 1970). At the same time, ants are known to recognize many objects by their scent. In particular, scent plays the major role in recognition of the slaves by slaver ants and in suppressing their aggression toward young heterospecific individuals (Jaisson, 1975), and also in recognition of family members in mutualistic species (Reznikova, 1975). The observed response of ants to the beetle wrapped in dark cloth suggests that chemical signals are used by ants to recognize the potential competitors among predatory invertebrates as well. An example of chemical recognition of a generalized "predator" among invertebrates is the spider mite Tetranychus urticae (Koch), which avoids the substrates with traces of excreta related to animal diet (Grostal and Dicke, 2000). The universal nature of such signals makes orientation much easier in many situations.

The characters attracting ants to the models of their competitors may form a certain hierarchy. The dark coloration and bilateral symmetry are the primary characters that attract the attention of ants. The white color of the model to a significant extent "deactivated" responses to movements, size, and even scent of the beetle. In the case of dark colored symmetrical models, such characters as movement, size, scent, and the presence of appendages complied to the "summation rule" (MacFarland, 1988); in other words, their effect on the behavior of ants was additive. For example, large models attracted more ants than small ones; moving models were more attractive than immobile ones; large and moving models were more attractive than either small moving ones or large stationary ones.

Ground beetles avoid individual contacts with moving ants, using a set of behavioral patterns that "switch on" in direct proximity of active ants. Stable changes in the beetle behavior, allowing them to avoid danger in repeating situations, can be regarded as learning. 
Even though ground beetles avoid encounters with active ants, the predatory species are attracted, rather than repelled, by the scent of ants. They are equally attracted by $F$. aquilonia, whose territory they inhabit, and $F$. pratensis, which they never encounter in nature. This means that ground beetles must respond to some olfactory characteristics common to Formica s. str. living in dome-shaped nests. Laboratory experiments showed that ground beetles could consume dead ants. This fact may explain the beetles being attracted to ant-controlled territories, because in the periphery of the red wood ant colonies there are "ant cemeteries," where dead ants are brought. The cemeteries of large colonies may provide an essential food source for the beetles. It is possible that behavioral patterns aimed at avoiding encounters with spatial competitors allows the ground beetles to enter ant-controlled territories and to use ant cemeteries as an additional source of food.

Thus, flexible behavioral responses, based on selection and effective use of available tactical patterns, provide the mechanism of the spatial segregation of ants and ground beetles inhabiting the same territory and facilitate a more complete utilization of resources by spatial competitors.

\section{ACKNOWLEDGMENTS}

The work was financially supported by the Russian Foundation for Basic Research (grant no. 05-0448604), the President's Council for Leading Academic School Support (grant no NSh-1038.2003.4), the Presidium of RAS Grant within the Program "The Origin and Evolution of Biosphere," and the Foundation in Support of National Science.

\section{REFERENCES}

1. Cherix, D. and Bourne, J.D., "A Field Study on a SuperColony of the Red Wood Ants Formica lugubris Zett. in Relation to Other Predatory Arthropods (Spiders, Harvestmen and Ants)," Rev. Suisse Zool. 87 (4), 955-973 (1980).

2. Dorosheva, E.A., "Behavior of Predatory Ground Beetle Species Aimed at Avoiding Encounters with Ants within Ant Nest Territories," in Proc. II All-Russia Soil Zoology Workshop (Moscow, 1999), pp. 187-188.

3. Gridina, T.I., "Influence of Formica polyctena Foerst. (Hymenoptera, Formicidae) on the Distribution of Predatory Arthropods in Forest Ecosystems," Memor. Zool. Acad. Pol. Sci. 44, 21-36 (1990).

4. Gridina, T.I., "Ethological Aspects of Interrelation between Formica polyctena Foerst. (Hymenoptera, Formi- cidae) and Spiders and Carabids," Memor. Zool. Acad. Pol. Sci. 48, 91-97, (1994).

5. Grostal, P. and Dicke, M., "Direct and Indirect Cues of Predation Risk Influence Behavior and Reproduction of Prey: a Case of Acarine Interaction," Behav. Ecol. 10 (4), 422-427 (2000).

6. Hawes, C., Stewart, A.J.A., and Evans, H.F., "The Impact of Woods Ants (Formica rufa) on the Distribution and Abundance of Ground Beetles (Coleoptera: Carabidae) in a Scots Pine Plantation," Oecologia 131, 612-619 (2002).

7. Inozemtsev, A.A., "Dynamics of the Trophic Associations of Red Wood Ants and Their Role in Regulation of Invertebrate Pests in Oakeries of Tula Province," Ekologiya (3), 62-75 (1974).

8. Jaisson, P., "L'impregnation dans l'ontogenese des comportements de soins aux cocons chez la jeune Formi rousse (Formica polyctena Foerst.)," Behaviour 52 (1-2), 1-37 (1975).

9. Kolbe, W., "Käfer im Wirkungsbereich der roten Waldameise," Entomol. Z. 7, 269-280 (1969).

10. Lovei, G.L. and Sunderland, K.D., "Ecology and Behavior of Ground Beetles (Coleoptera: Carabidae), Annu. Rev. Entomol. 41, 231-256 (1996).

11. MacFarland, D., The Oxford Companion to Animal Behavior (Oxford Univ. Press, New York, 1982; Mir, Moscow, 1988) [in Russian].

12. Malozemova, L.A., "Some Biological Traits of the Red Wood Ant in the Mountain Taiga of Northern Urals," in Fauna of the Urals and Northern Europe (Sverdlovsk, 1980), pp. 78-87 [in Russian].

13. Niemelä, J., "Spatial Distribution of Carabid Beetles in the Southern Finnish Taiga: a Question of Scale," in Ground Beetles: Their Role in Ecological and Environmental Studies, Ed. by N.E. Stork (Intersept Publ., Andover, 1990), pp. 143-155.

14. Pollard, J.H., A Handbook of Numerical and Statistical Techniques (Cambridge Univ. Press, Cambridge, 1977; Finansy i Statistika, Moscow, 1982) [in Russian].

15. Reznikova, Zh.I., "Non-Antagonistic Interactions between Ants Occupying Similar Niches," Zool. Zh. 54 (7), 1020-1031 (1975).

16. Reznikova, Zh.I., Interspecific Interactions in Ants (Nauka, Novosibirsk, 1983) [in Russian].

17. Reznikova, Zh.I., Populations and Species: a 'War or Peace' Concept (Logos, Moscow, 2001) [in Russian].

18. Reznikova, Zh.I., "A New Pattern of Interspecific Relations in Ants: the Hypothesis of Interspecific Social Control," Zool. Zh. 82 (7), 816-824 (2003) [Entomol. Rev. 83 (9), 1184-1193 (2003)].

19. Reznikova, Zh.I. and Dorosheva, E.A., "Effect of Red Wood Ants on the Behavior of Ground Beetles: Experiments with Individual Insects," Doklady Ross. Akad. Nauk 375 (4), 571-573 (2000).

20. Reznikova, Zh. and Dorosheva, E., "Impacts of Red Wood Ants Formica polyctena on the Spatial Distribu- 
tion and Behavioral Patterns of Ground Beetles," Pedobiologia 48, 15-21 (2004).

21. Reznikova, Zh.I. and Novgorodova, T.A., "Individual Roles and Information Exchange in Groups of Ant Workers," Uspekhi Sovrem. Biol. 118 (3), 345-356 (1998).

22. Robinson, M.H., "Insect Antipredator Adaptations and Behavior of Predatory Primates," Congr. Latin Zool. 2, 811-836 (1970).

23. Rybalov, L.B., Rybalov, G.L., and Rossolimo, T.E., "Effect of Red Wood Ants on Litter-Dwelling Predators in Kostomuksha Nature Reserve," Uspekhi Sovrem. Biol. 118 (3), 313-322 (1998).
24. Sergeeva, T.K., "Serological Characterization of Trophic Associations and Resource Distribution in the Predatory Ground Beetle Assemblage," Uspekhi Sovrem. Biol. 112 (3), 32-41 (1992).

25. Suvorov, A.A., "Effect of Red Wood Ants on the Community Structure of Litter-Dwelling Invertebrates in Spruce Forests of Moscow Area," in Edaphic Fauna of Moscow Province (Nauka, Moscow, 1994), pp. 74-99 [in Russian].

26. Tinbergen, N., The Study of Instincts (Oxford Univ. Press, Oxford, 1951).

27. Zakharov, A.A., "Ecology of Ants," Itogi Nauki Tekhniki 17, 132-205 (1980). 